\title{
Toward a Theory for the Design of Human Technologies
}

Simonsen, Jesper; Hertzum, Morten; Nielsen, Jørgen Lerche; Riis, Søren

Published in:

$\mathrm{OzCHI}$ '14 Proceedings of the 26th Australian Computer-Human Interaction Conference on Designing Futures: the Future of Design

DOI:

$10.1145 / 2686612.2686682$

Publication date:

2014

Document version

Publisher's PDF, also known as Version of record

Citation for published version (APA):

Simonsen, J., Hertzum, M., Nielsen, J. L., \& Riis, S. (2014). Toward a Theory for the Design of Human Technologies. In $\mathrm{OzCHI}$ '14 Proceedings of the 26th Australian Computer-Human Interaction Conference on Designing Futures: the Future of Design (pp. 444-447). Association for Computing Machinery. Australasian Computer Human Interaction Conference. Proceedings https://doi.org/10.1145/2686612.2686682 


\section{Toward a Theory for the Design of Human Technologies}

\author{
Jesper Simonsen \\ User-Driven IT Innovation \\ Dept. of Communication, Business and IT \\ Roskilde University \\ simonsen@ruc.dk \\ Jørgen Lerche Nielsen \\ Dialogic Communication \\ Dept. of Communication, Business and IT \\ Roskilde University \\ jln@ruc.dk
}

\author{
Morten Hertzum \\ Royal School of Library and \\ Information Science \\ University of Copenhagen \\ hertzum@acm.org \\ Søren Riis \\ Science Studies \\ Dept. of Culture and Identity \\ Roskilde University \\ soerenr@ruc.dk
}

\begin{abstract}
Design is increasingly becoming a part of the university curriculum and research agenda. A theory about the process and practice of design might be important to establish design as a main subject at universities. We believe it is in the interest of many design communities - not least the Participatory Design (PD) community - to engage in theorizing design, on the basis of our understanding of design and design practices. This theory could be positioned as an alternative to other attempts to theorize design, for example the influential efforts of the Information Systems (IS) community. We urge the PD community to engage in collective theory building, and we present a framework intended to support our shared reflections on the design of human technologies.
\end{abstract}

\section{Author Keywords}

Design, theory, epistemology, framework.

\section{ACM Classification Keywords}

H.1.1 Systems and Information Theory

\section{INTRODUCTION}

Human and societal problems are to a considerable extent addressed with technological means, and there is widespread recognition of the importance of technology in ensuring our welfare in the future. The design of new technologies has also become the subject of universitybased research and led to new educational programs. In Europe, schools within design and architecture have traditionally been rooted in practice and craftsmanship but now increasingly implement academic criteria in their programs. The emergence of university curricula that approach design on a scientific basis creates a need to theorize the practices and processes of designing.

Within IS a widely cited attempt to characterize design science suggests a conceptual framework combining interactions of build-evaluate iterations with the environment and business needs (stressing relevance) as well as the use of, and contribution to, the existing knowledge

Permission to make digital or hard copies of all or part of this work for personal or classroom use is granted without fee provided that copies are not made or distributed for profit or commercial advantage and that copies bear this notice and the full citation on the first page. Copyrights for components of this work owned by others than ACM must be honored. Abstracting with credit is permitted. To copy otherwise, or republish, to post on servers or to redistribute to lists, requires prior specific permission and/or a fee. Request permissions from Permissions@acm.org.

OzCHI '14, December 02 - 05 2014, Sydney, NSW, Australia Copyright 2014 ACM 978-1-4503-0653-9/14/12...\$15.

http://dx.doi.org/10.1145/2686612.2686682 base (stressing rigor) (Hevner et al., 2004). The framework is accompanied by seven general guidelines "in order to illustrate how authors, reviewers, and editors can apply them consistently" (p. 76). We believe that such frameworks play an influential role in establishing design as a scientific discipline at the universities. IS has a focus on business, management, and organization. Their frameworks do, however, not explicitly address all issues and concerns of other design communities.

How should PD, and other communities involved in the design of human technologies respond to the challenge of theorizing design? We suggest that they should engage in developing design theories that embrace our understanding of design and the core identity of our communities. There is, we contend, a need for a science-based, designoriented main subject at the universities to explain the role of technologies in contemporary societies, to conceptualize the contributions of designing to fulfilling human needs, and to provide a foundation for the education of future academic designers. We propose building frameworks that acknowledge design as "a process of investigating, understanding, reflecting upon, establishing, developing, and supporting mutual learning between multiple participants in collective 'reflection-in-action"' (Simonsen and Robertson, 2012, p. 2). In addition, we emphasize multiplicity rather than a universalistic worldview, and collective reflections rather than a position of "all learning takes place inside individual human heads" (Simon, 1991, p. 125).

A design-oriented main subject at the universities should embrace broad approaches to design and include multiple, diverse, interdisciplinary subject areas, application domains, researchers, and projects. At Roskilde University, Denmark, we have since 2008 strived to establish a new main subject area - Designing Human Technologies alongside the three longstanding main subject areas: Natural Science, the Humanities, and Social Science. The purpose of this design-oriented area is to be constructive (to make designs) and solution-oriented in close dialogue with citizens, users, and other stakeholders in design projects. The university's contribution toward fulfilling this purpose is (1) to provide an analysis of the relevant issues, (2) to design solutions for specified issues through, for example, action research, and (3) to reflect on how designs are used and incorporated in human lives. We 
subscribe to the basic human principle that users, target groups, and other central stakeholders must take part in the design and the design process, in ethical and societyrelated discussions, and in evaluating how designs fulfill needs and solve problems. Designing Human Technologies espouses a broad conception of technology, including information, communication, mobile, environmental, and energy technologies as well as technologies relating to performances, experiences, urban design, climate adaptation and so forth.

One of our key activities has been engaging in collectively discussing and reflecting upon our different design project experiences. This has led to two recent anthologies in which a total of 46 researchers reflect on 33 design projects dealing with organization and information technology design in for example the health sector, the design of urban spaces, the design of performances and museum events, and the design of environment-friendly alternative technologies in the transport sector. In spite of diverse backgrounds, our reflections have uncovered a shared understanding of the design process depicted in a general process model that emphasizes the emergent properties of design (Simonsen et al., 2010) and in a collection of 18 situated methods for design (Simonsen et al., 2014).

We do not mean to suggest that existing work in PD, human-computer interaction, and related fields has not produced and been informed by theory. It has. What we do mean to propose is that further theorizing about design in PD and related fields should preferably be a collective process anchored in the experiences of multiple research groups, their projects, and disciplinary backgrounds. Based on our experiences so far, we present an initial design framework and propose using it to stimulate and coordinate a dialogue about shared theory building. The framework is at an early stage of development and intended to evolve over the coming years.

\section{AN INITIAL DESIGN FRAMEWORK}

Our initial framework consists of four themes, each characterized by four dimensions, see Figure 1. We hope the framework can serve as a vehicle for researchers with different backgrounds to reflect on their design experiences.

\begin{tabular}{|c|c|}
\hline $\begin{array}{l}\text { Change } \\
\text { - Planned } \\
\text { - Emergent } \\
\text { - Opportunity-based } \\
\text { - Sustainable }\end{array}$ & $\begin{array}{l}\text { Participation } \\
\text { - } \quad \text { Different knowledges } \\
\text { - } \quad \text { Mutual learning } \\
\text { - } \quad \text { Joint goal negotiation } \\
\text { - } \quad \text { Infrastructuring }\end{array}$ \\
\hline $\begin{array}{l}\text { Situatedness } \\
\text { - } \quad \text { Situated knowledges } \\
\text { - } \quad \text { Situated learning } \\
\text { - } \quad \text { Situated action } \\
\text { - } \quad \text { Situating contexts }\end{array}$ & 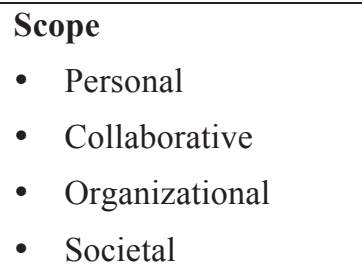 \\
\hline
\end{tabular}

Figure 1. A framework intended for supporting reflection on the design of human technologies.

Design processes aim to produce change, the first theme of our framework. Simon (1996) considers this aim the defining characteristic of design when he states that "everyone designs who devises courses of action aimed at changing existing situations into preferred ones" (p. 111). The relation between design and change is, however, dynamic and unruly. Many studies find that change defies detailed planning, that the changes resulting from a design may contradict the changes that motivated the design, and that the changes that accompany a design may not persist. In the last case, the preferred situation reverts back into the old situation, or transforms into a third situation, thereby suggesting that the design process was based on a partial understanding of the preferred situation. While this can be considered evidence of substandard design work, it is increasingly perceived as an unavoidable condition we need to face in our understanding of design and change. One response is to broaden the conception of design to include also the activities that produce the changes not initially planned for (e.g., Dittrich et al., 2002).

We distinguish between four dimensions of change: Planned change is intended, planned ahead, and occurs as anticipated by the originators of the change. Emergent change is local and spontaneous. It grows out of practice, rather than happens as the result of deliberate and originally planned action. Opportunity-based changes are purposefully introduced changes resulting from unexpected opportunities, events, or breakdowns that arise after the introduction of a new technology (Orlikowski \& Hofman, 1997). Sustainable change implies that changes must accord with ideological, moral, and ethical points of view and must strive for a small ecological footprint in terms of their environmental effects and consumption of resources.

The second theme of our framework is participation. Participation involves that representatives of all actors with a stake in the use of the designed technology must take part in the process of its design. Taking part means that "any user needs to participate willingly as a way of working both as themselves (respecting their individual and group's/community's genuine interests) and with themselves (being concentrated present in order to sense how they feel about an issue, being open toward reflections on their own opinions)" (Simonsen and Robertson, 2012, p. 5). This definition stresses the conditions necessary for genuine participation in projects. In the absence of the necessary conditions user representatives may face a troubling tension between their role as representatives of their group and that as members of the design project. In addition to personal authenticity, participation is normally associated with genuine influence. This way, participation, for example, goes beyond user roles such as those of being an informant in interviews aimed at gathering user needs or a subject in evaluations aimed at identifying usability or efficiency problems.

Participation encompasses some of the basic principles of participatory design (Simonsen and Robertson, 2012). We recognize the importance of respect for different knowledges, which is a prerequisite for participation to occur, and of the commitment to mutual learning, which means that designers must learn about the realities of the users' work and the users must learn about available technologi- 
cal options to be able to articulate their desired aims. In addition, the dimensions of participation include joint goal negotiation to achieve "shared and agreed-upon goals of the design task and project at hand" (Simonsen and Robertson, 2012, p. 5). Infrastructuring, the final dimension of participation, involves that participation serves to make designs part of existing structures and practices. Participation introduces user needs and situational constraints that shape design products and, at the same time, participation results in design products that shape the structures and practices.

Design is inextricably woven into the particulars of the situation in which the design takes place. It is situated. This third theme of our framework is in opposition to a universalistic view of design as an activity for which we can devise principles and methods that apply unaltered across situations. It is, however, also in opposition to a relativistic view of design because such a view treats all situations as different but equally important and, thereby, refrains from engaging with the particulars of the concrete design situation. Viewing design as situated means that the situation with its possibilities, constraints, and other particulars co-determines the design process and the resulting design. It also means that what is being designed is a transformation of the situation, not merely an add-on to it (Simonsen et al., 2014). The situation shapes the design process, positively as well as negatively; it is not simply a passive background upon which the design takes place.

We identify four related but different ways of approaching situatedness: Situated knowledges imply that design is always carried out with partiality and from a specific, embedded position, as "politics and epistemologies of location, positioning, and situating" (Haraway, 1988, p. 589). Situated learning emphasizes design processes and designers' learning as embedded in communities of practice (Lave and Wenger, 1991). Situated action emphasizes the role and pervasiveness of "ad hoc improvisation the part of us, so to speak, that actually acts" (Suchman, 2007, p. 71), as opposed to representations of action in the form of prescriptive accounts such as plans, procedures, and guidelines. Situating contexts (Simonsen et al., 2014) point to the multiple relations between the societal context and the design situation, including structures given by institutions, regulation, market mechanisms, and infrastructures.

The fourth theme of our framework is scope. Design projects, technologies, and associated use situations may differ drastically in scope. Some have argued that researchers should to a larger extent engage in projects with a wider scope (e.g., Shapiro, 2005). Whereas PD projects have often focused on technologies with a collaborative or organizational scope, overarching issues, such as workplace democracy, are societal in scope. In addition, technological infrastructures may have consequences for individuals, organizations, as well as societies and, therefore, warrant analyses and design efforts at multiple levels of scope. Different levels of scope demand different types of change management, create different conditions for participation, and entail situated design activities with different extents of partiality and heterogeneity.
At the most intimate level, the scope is personal and focuses on individuals' motivation for interacting with a technology, their experiences from using and incorporating technologies in their lives, and their reasons for taking part in design processes. A collaborative scope concerns design processes, technologies, and use situations that bring multiple people together, often across professions, disciplines, seniority levels, age groups, and other boundaries. The scope of design work is frequently organizational as emphasized within IS. Thereby, design becomes entangled in managerial decisions, organizational communication structures, employee motivation, and the like. At the same time, a scope corresponding to an organization provides better opportunities for managerial support than designs targeting the collaborative processes of subgroups within organizations. Finally, design work may have a societal scope. At this macro level sustainability, infrastructures, social development, technological regimes, and the cultivation of alternative design spaces are among the important issues.

\section{DISCUSSION}

The primary interest of designers has to do with changing things, connecting entities, and altering the world we are living in. Whereas natural scientists are preoccupied with descriptive analysis of nature, designers are engaged with normative constructions. We may express these differences by asserting that ontology is to the natural sciences what epistemology is to the field of design. It is in this sense crucial that the designers know the meaning and implications of the four themes in the framework we have outlined above. The designers of course also need to know the materials they are working with, but this only as means toward a different end, namely change, alteration, adjustment, improvement and so forth. Due to the normative quality of design, we maintain that design does not merely build on a priori knowledge, but continuously needs to reflect on previous design experiences and its own history. We also maintain that designers need to operate interdisciplinarily to make good designs in line with the four themes of the framework.

The framework is deliberately not referencing any specific disciplines or application domains. Our intention is to suggest a framework enabling researchers to engage in collaborative and coordinated reflections independently of disciplinary perspectives, such as computer science, informatics, sociology, geography, organization studies, performance design, urban studies, communication, and education, as well as independently of application domains, such as government, engineering, healthcare, service design, education, sustainable production, public exhibitions, performances, and tourist experiences.

A theory for the design of human technologies must synthesize the extensive empirical experience acquired by design researchers. This entails a focus on learning with an emphasis on mutual learning. New paradigms have emerged with a greater focus on how learning and knowledge are created through the interaction and active participation of researchers as well as practitioners in collaborative design processes. Within education, students as well as professors engaged in mutual learning must be aware of what they are doing, and how they are 
interacting while they are doing it, to paraphrase Schön (1983, p. 275). Due to the complexity of the processes, activities can only be planned tentatively and through continuing iterations. It is therefore necessary for the participants - be it students, professors or practitioners to engage in dialogues and negotiations in order to reach strategies for action. Barab and Squire (2004) explain that a design-based research approach in relation to learning means:

- Approaching the study of learning in real world settings through ethnographic methods.

- Producing new insights and theory through interventions in praxis.

- Conducting iterative processes; that is, cycles of design, implementation, analysis, evaluation, and redesign.

- Involving researchers as well as practitioners.

- Applying a pragmatic approach oriented toward improving the setting of the intervention.

Communities of researchers engaged in design processes should systematically exchange their findings and experiences, and collaborate in reflecting on how each project contributes to the joint development of a design theory. We plan to use our framework to organize such collective cross-project reflections. To work through the experiences from a project, they can be structured by and reflected into the four themes and 16 dimensions of the framework. The reflections must address how a project has worked with a theme/dimension and what this work resulted in, in terms of knowledge as well as designs. Both 'how' and 'what' questions are important. As a guide, we suggest the following generic questions to stimulate reflection about design experiences on the basis of the framework:

Reflect on the experiences from a given project as related to one or more of the themes/dimensions in Figure 1:

- What are the conditions and context of the theme/dimension in this project?

- How did it 'unfold', how would you describe it?

- How did you strive to respond appropriately to it?

- What were the challenges and opportunities involved?

- How have you (or others) tried to counter these challenges and make use of the opportunities?

The aim of these questions is to stimulate reflection about the interactions involved in a given context including learning processes, knowledge sharing, and diffusion. Reflections may also concern principles for conducting genuine design processes as well as conditions that might hinder or facilitate them. Finally, reflections on aesthetics, ethics, values, connections to politics, and strategies for enabling a better future should be recognized as legitimate when theorizing design. We recognize that the questions, and the framework at its current stage, are stronger in what Halverson (2002) terms descriptive and rhetorical power and less developed in inferential and application power. That is, our initial framework is a vehicle for reflecting on design processes, not for devising them.
A theory for the design of human technologies should be interdisciplinary, and in order to achieve this objective the approach to theorizing design must be inclusive. Our aim is to provide a meeting point for a plurality of voices, to stimulate discussion across different perspectives, knowledges, and ontologies, and to shed light on design as it is practiced in different contexts. Patterns in the contributions to such a theory might well emerge and stabilize but should not be taken for granted. Rather, the theory should itself remain open to change, invite participation, embrace its situatedness, and strive to interconnect multiple levels of scope.

\section{REFERENCES}

Barab, S.A. and Squire, S. Design-based research: Putting a stake in the ground, Journal of the Learning Sciences, 13(1) (2004), 1-14.

Dittrich, Y., Eriksén, S. and Hansson, C. PD in the wild: Evolving practices of design in use. Proc. PDC 2002, ACM Press (2002), 124-134.

Halverson, C.A. Activity theory and distributed cognition: Or what does CSCW need to do with theories? Computer Supported Cooperative Work, 11(1-2) (2002), 243-267.

Haraway, D. Situated knowledges: The science question in feminism and the privilege of partial perspective, Feminist Studies, 14(3) (1988), 575-599.

Hevner, A.R., March, S.T., Park, J. and Ram, S. Design science in information systems research. MIS Quarterly, 28(1) (2004), 75-105.

Lave, J. and Wenger, E. Situated learning: Legitimate peripheral participation, Cambridge University Press, Cambridge, UK (1991).

Orlikowski, W. and Hofman, D. An improvisational model for change management: The case of groupware technologies. Sloan Management Review, 38(2) (1997), 11-22.

Schön, D.A. The reflective practitioner. Basic Books, NY, USA (1983).

Shapiro, D. Participatory design: The will to succeed. Proc. Critical Computing (2005), 29-38.

Simon, H.A. Bounded rationality and organizational learning. Organization Science, 2(1) (1991), 125-134.

Simon, H.A. The sciences of the artificial. Third edition. MIT Press (1996), Cambridge, MA, USA.

Simonsen, J., Bærenholdt, J.O., Büscher, M. and Scheuer, J.D. (eds) Design research: Synergies from interdisciplinary perspectives, Routledge, London, UK (2010).

Simonsen, J. and Robertson, T. (eds) Routledge international handbook of participatory design, Routledge, London, UK (2012).

Simonsen, J., Svabo, C., Strandvad, S.M., Samson, K., Hertzum, M. and Hansen, O.E. (eds) Situated design methods, MIT Press, Cambridge, MA, USA (2014).

Suchman, L.A. Human-machine reconfigurations: Plans and situated action, 2nd edition, Cambridge University Press, Cambridge, NY, USA (2007). 